\title{
3D Numerical Investigation of Ground Settlements Induced by Construction of Istanbul Twin Metro Tunnels with Special Focus on Tunnel Spacing
}

\author{
Behnaz Hallaji Dibavar ${ }^{1 *}$, Mohammad Hossein Ahmadi², Seyed Morteza Davarpanah³ \\ 1 Department of Mining Engineering, Hacettepe University, 06800 Beytepe, Ankara, Turkey \\ 2 Department of Mining and Metallurgical Engineering, Amirkabir University of Technology, 424 Hafez Ave, Tehran, Iran \\ ${ }^{3}$ Department of Engineering Geology and Geotechnics, Faculty of Civil Engineering, Budapest University of Technology and \\ Economics, H-1521 Budapest, P.O.B. 91, Hungary \\ * Corresponding author, e-mail: behnaz.dibavar@hacettepe.edu.tr
}

Received: 25 June 2019, Accepted: 06 October 2019, Published online: 10 December 2019

\begin{abstract}
One of the most important considerations of tunneling in urban areas is controlling the amount of surface settlement that occurs during construction stages. The goal of this paper is to investigate the effect of spacing of Istanbul Twin Metro Tunnels on the surface settlement excavated by NATM method in YENIKAPI-UNKAPANI metro line. For this purpose, the focus has been placed on the effect of longitudinal and transversal spacing between tunnels supported by an umbrella arch protecting method. (FLAC3D) was implemented to simulate the excavation sequence. According to the analysis, the amount of settlement by numerical approach was about $23.5 \mathrm{~mm}$ which was in good agreement with the field monitoring results that was $26.5 \mathrm{~mm}$. Moreover, the interaction between twin tunnels by the increase in spacing between twin tunnels in the direction perpendicular to tunnel axis decreases and becomes less effective at the location about 3 times of the tunnel diameter. Similarly, the interaction between twin tunnels in the direction parallel to tunnel axis decreases as the spacing increases. In other words, by increasing the distance between tunnel faces in longitudinal direction at a distance about 3 times of the tunnel diameter, there is still interaction between tunnels and it doesn't disappear completely. Therefore, it is recommended to keep this distance at about more than 2.5 times of tunnel diameter so that settlement can stay within acceptable range. Keywords
\end{abstract}

surface settlement, NATM method, umbrella arch protecting method, FLAC 3D

\section{Introduction}

Due to growing population of the world, the need for underground transportation, especially metro tunnels in urban areas has increased significantly. One of the inevitable issues during tunneling in such areas is the surface movements and displacements as a result of excavation. It is of high importance because of the sensitivity of adjacent structures to possible surface settlements.

In respect to our research, NATM method, the ground itself withstands part of stress relaxation. In this method, in order to stabilize the face of tunnel prior to excavation, an umbrella arch protecting method is usually applied. Using this method, strengthens the stability of the host ground of tunnel, increases the stability of tunnel face, and also decreases the surface settlement.

As it is well-known, in twin tunnel excavation, if the tunnel faces are too close to each other, it causes disturbance zones, large displacements at tunnel crown, and consequently large surface settlements. Therefore, the aim of this research is to reach the optimal spacing between twin tunnel faces to minimize the influence of disturbance zones effect on each other.

According to the literature, using a variety of approaches such as physical model testing, field observations, empirical/analytical methods, and finite element modeling, interactions between closely-spaced tunnels were investigated in the past [1-10].

Kim et al. [11] performed a reduced-scale physical model testing to study the interaction between closely spaced twin tunnels in clay. It was found that the displacement and moment interaction effects increase as the spacing between twin tunnels is reduced, and it is small when the distance between tunnels is more than 1.5D ( $\mathrm{D}=$ tunnel dimeter). 
$\mathrm{Ng}$ et al. [12] performed a series of three-dimensional numerical simulation to investigate the multiple interactions between large parallel twin tunnels constructed using the new Austrian tunneling method. Special attention was paid to the influence of lagging distance between the twin tunnel excavated faces $\left(\mathrm{L}_{\mathrm{T}}\right)$ and the load-transfer mechanism between the tunnels. It was found that $\mathrm{L}_{\mathrm{T}}$ has a stronger influence on the horizontal movement than on the vertical movement of each tunnel and the magnitude of the maximum settlement is independent of $\mathrm{L}_{\mathrm{T}}$. They found that at $\mathrm{L}_{\mathrm{T}}=2.5 \mathrm{D}$ the location of the maximum surface settlement which offsets the centerline of the pillar due to the construction of the twin tunnels approaches a fixed position. The magnitude of the bending moments was largest in the leading tunnel and smallest in the lagging tunnel.

Chapman et al. [13] described the influence of tunnel distance, tunnel depth and tunnel number on short term ground movements using a small scale laboratory model in a lightly over-consolidated clay sample. Results showed greater movements above the second tunnel constructed. They also concluded that settlement profile, when the settlements from the first and second tunnels are summed, is very different to that obtained using the assumption of Gaussian curves.

For most rock materials, there exists a strong coupling between plastic flow caused by sliding along microcrack faces and damage evolution due to nucleation and growth of wing-cracks. Also the Excavation damage zone (EDZ) between twin tunnels can be estimated by damage models [14].

Ocak [15] investigated the effects of umbrella arch method on surface settlements in excavation of the second stage of Istanbul Twin Metro Tunnels and concluded that applying this method decreases the surface settlements by 3 times when tunnels are excavated by NATM method.

In the study by Chakeri et al. [16] the changes in stress distribution, deformations and surface settlements which may be induced by constructing twin tunnels under a single tunnel are simulated using full 3D numerical finite difference method. It was concluded that the surface settlement depends on the spacing between twin tunnels and the effects of constructing perpendicularly crossing tunnels on the tunnel lining of existing adjacent tunnels are noticeable.

Ercelebi et al. [17] presented field measurements conducted on parallel twin tunnels excavated using EPB TBM shields in Istanbul metro tunnels. To predict the surface settlements, they used Plaxis finite element program, semi theoretical and analytical methods. Results showed that the
FE model predicts well the short time surface settlements for a given volume loss value but some semi theoretical and analytical methods overestimate the surface settlements.

Hasanpour et al. [18] carried out numerical and semi empirical analysis to predict the maximum surface settlement above the twin tunnels pre supported by pipe roofing and excavated by NATM method. It was found that the Settlement above the tunnel crown is reduced by $65 \%$ when a pipe roofing reinforcement is installed and beyond a distance of 5D the construction of the first tunnel does not affect the second one. They concluded that Herzog model yields higher maximum surface settlements than the measured ones due to ignoring the effects of supporting systems.

Ocak [19] carried out field measurements and considered surface settlements in Istanbul twin metro tunnels between Otogar-Kirazli excavated by EPBM. They observed that the transverse surface settlement curve mostly inclined toward to the second tunnel and the volume loss value of the second tunnel was greater than that of the first tunnel.

Ling Ma et al. [20] proposed a double peak Gaussian model of settlement trough by extending Peck's formula. They used a large amount of settlement data accumulated from a metro tunnel project in China and implemented two numerical methods in data exploration. They recommended to use this model in describing the later stage of settlement trough.

Fang et al. [21] investigated the ground surface settlements due to construction of closely spaced twin tunnels excavated by NATM using the shallow tunneling method. They concluded that increasing the distance between twin tunnels causes the ground loss percentages induced by the excavation of the second tunnel to decrease. They also observed that the parameters such as trough width and ground loss percentage are greatly influenced by the ground reinforcement schemes.

In a paper published by Davarpanah et al. [22], regression analyses between the NSPT and the uniaxial compression strength test and the pressure meter test parameters obtained from a geotechnical investigation were carried out to investigate the displacement due to full face tunnel excavation of Tabriz subways. The obtained results showed interesting correlation between measured data.

\section{Site geology}

The excavation of the second stage of Istanbul Twin Metro Tunnels was carried out in formations which generally consist of sandstone, siltstone, claystone, and shale sequences (Trakya formation). In addition, there are some 
limestone and conglomerate layers in the area. The geological structure in the south part of tunnels is divided into three main units consisting of loos gravel-sand-silt, clay-marl layer, and limestone-shale-marl sequences (Güngören formation) [23]. A formation which is locally named Sülaymaniye lies on top of the Trakya formation, and includes claystone and marl with interbedded clay and sand horizons [24]. The height of the overburden from tunnel centers to the ground surface varies between 11 and $42 \mathrm{~m}$ throughout the metro line, and the horizontal distance between twin tunnels is between 30 and $32 \mathrm{~m}$ [15].

In this study, the investigated results of twin tunnels behavior as passing through homogenous soil at $4+657$ kilometer is illustrated. At this section, the entire tunnel is located in Trakya Formation and the height of overburden from tunnel center is about $14.85 \mathrm{~m}$. The geological structure of the studied area is presented in Fig. 1. Along the route of the twin tunnels, which have a length of $5200 \mathrm{~m}$, 76 exploration boreholes and 20 geothecnical monitoring and measurement boreholes have applied in order to determine the geotechnical properties of the area. The total depth of these drillings opened during feasibility and implementation stages is $2614.05 \mathrm{~m}$ and were performed by rotary and percussion drilling methods.

In order to determine physical and mechanical properties, soil and rock mechanics tests were performed on the samples taken from the excavation faces along the Yenikap1-Unkapan1 route of tunnels. These tests include the measurements of properties such as unit weight $\left(\mathrm{kN} / \mathrm{m}^{3}\right)$, prosity, void ratio, water content, and modulus of elasticity.
Besides, the cohesion and internal friction angle values of soil in Trakya formation obtained from triaxial compressive strength tests. Geotechanical properties of studied area based on laboratory and field measurements presented in Table 1.

The tunnel cross section area is about $36 \mathrm{~m}^{2}$ and excavated in two stages shown in Fig. 2. The upper bench is $28 \mathrm{~m}^{2}$, and the lower bench is $8 \mathrm{~m}^{2}$. First, upper bench was excavated and then at the distance about $2.4 \mathrm{~m}$ from that the lower bench was excavated and this distance was maintained during excavation stages.

\section{Numerical modelling}

FLAC3D (Fast Lagrangian Analysis of Continua in 3 Dimensions) is a finite difference modeling program and is used for geotechnical analysis of underground structures constructed in soil and rock, such as metro tunnels

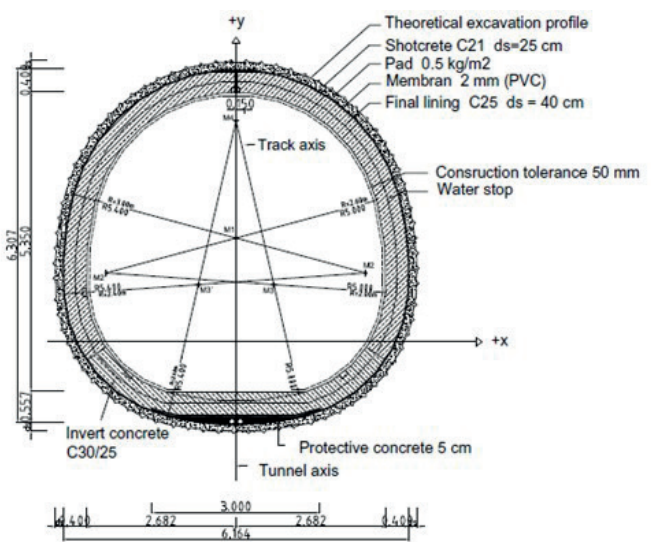

Fig. 2 Tunnel cross section [15]

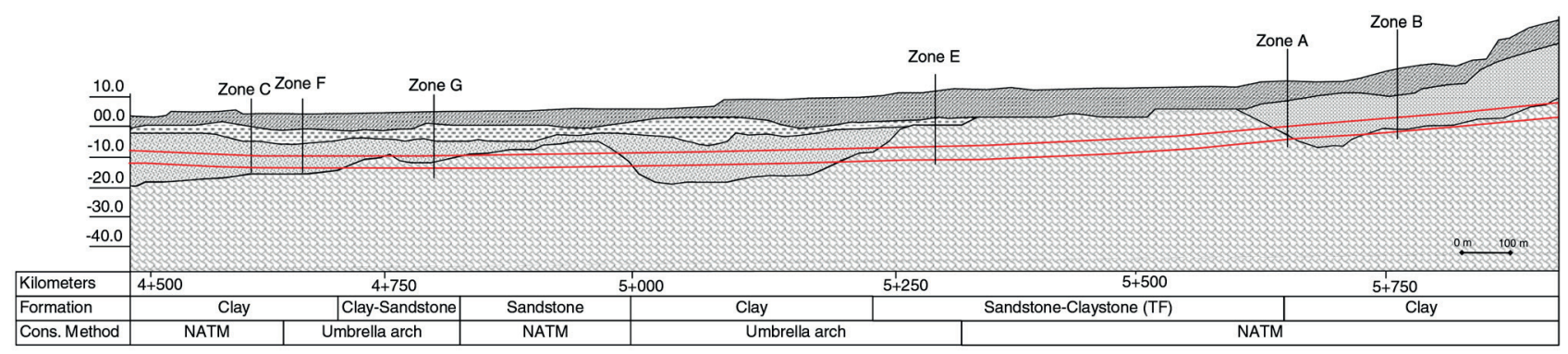

Sand Clay Trakya formation (TF)

Fig. 1 Geological cross-section of studied field [15]

Table 1 Geotechanical properties of studied cross section [23]

\begin{tabular}{lccccc}
\hline & Unit weigh $\left(\mathrm{KN} / \mathrm{m}^{3}\right)$ & Modulus of elasticity $\left(\mathrm{kN} / \mathrm{m}^{2}\right)$ & Cohesion $\left(\mathrm{kN} / \mathrm{m}^{2}\right)$ & Poisson ratio & Angle of friction \\
\hline Artificial filling & 18 & 5000 & 1 & 1 & 0.4 \\
Sand & 17 & 15.000 & 25 & 0.35 \\
Sülaymaniye formation & 18.9 & 38.000 & 0.33 & 0.2 \\
Trakya formation & 25 & 60.000 & 80 & 25 \\
\hline
\end{tabular}


and mines. This program is used for numerical modelling of twin tunnels of Istanbul metro in this study. The created model is oval in shape and $6.64 \mathrm{~m}$ and $6.30 \mathrm{~m}$ in horizontal and vertical diameter, respectively. The length of the model in $\mathrm{x}$ direction changes between $92 \mathrm{~m}$ (approximately $5 \mathrm{D}$ ) and $68 \mathrm{~m}$ (approximately 1.5D) where $D$ is the equivalent diameter of a tunnel equal to $6.16 \mathrm{~m}$. Fig. 3 shows 3D model and its dimensions. It presents excavation stages and meshes of twin tunnels. The length of model in the direction parallel to tunnel axis is $54 \mathrm{~m}$ and its height is $38 \mathrm{~m}$. The number of created zones in this model is 200000 . Their axis coincides with tunnel axis and in this direction the meshing system was chosen based on excavation stage. The excavation step was considered $1.2 \mathrm{~m}$.

At each node of the solid elements, there are three degrees of freedom describing displacements in the $\mathrm{x}, \mathrm{y}$, and $\mathrm{z}$ directions. In the simulation, lattice girders and umbrella arch pipes are modeled by the beam elements. At each node of the beam elements there are six degrees of freedom: three for displacements and three for rotations. The movements in all directions and rotations are fixed at

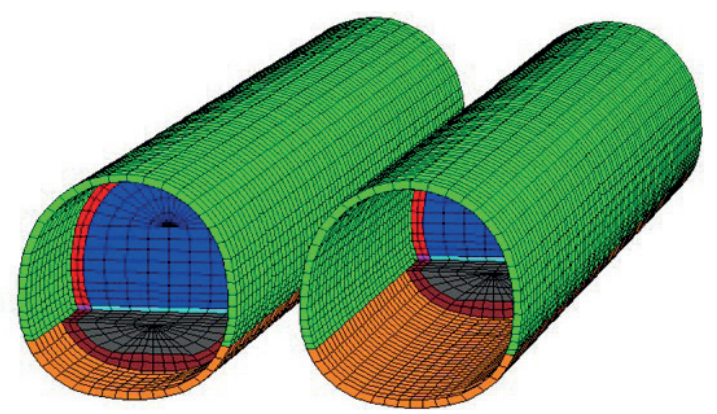

(a)

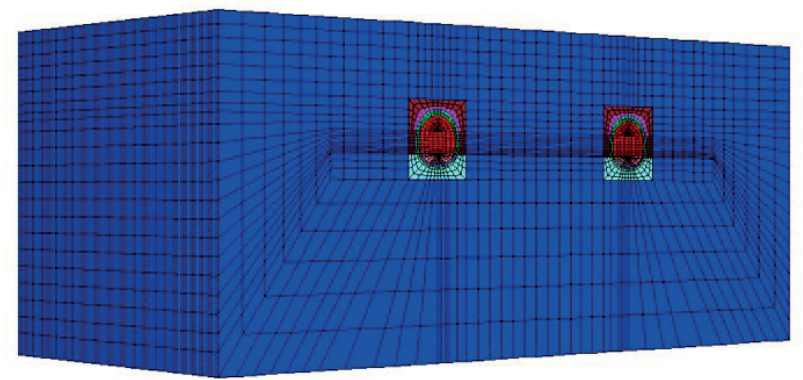

(b)

Fig. 3 Three-dimensional isometric view of the finite difference mesh of twin tunnels the bottom of the mesh and no horizontal displacements are permitted on the two $\mathrm{x}-\mathrm{z}$ planes (i.e., $\mathrm{y}=0$ and $\mathrm{y}=54$ ) at the boundaries of the mesh. In order to simulate shotcrete element, the volumetric elements were implemented in Flac3D. The thickness of shotcrete was $25 \mathrm{~cm}$. Lattice girders was modeled by applying beam elements. They were set at $0.6 \mathrm{~m}$ intervals. The distance of last lattice girder from tunnel face is about $0.6 \mathrm{~m}$. The length of piping steels in this project is $9 \mathrm{~m}$ and the length of overlapping is $3 \mathrm{~m}$. The mechanical properties of support system are presented in Table 2.

After creating model, material behavior was set to defined zones. It is assumed that the soil is isotropic and homogenous, and Mohr-Coulomb model was applied as constitutive model for analysis. Mohr-Couloumb material behavior is a widely-used model for rock and soil $[16,18]$. Regarding the required parameters and their accuracy, Mohr-Coulomb criterion is easy to use. This model assumes the stress-strain relation to be linear elastic-perfectly plastic requiring five input parameters to express the stress-strain behavior, and its failure criterion is named Mohr-Coulomb's failure criterion. The MC model is a basic model of soil and represents a first-order approximation of soil behavior. The stiffness parameters are constant in this model. In other models, such as Hardening Soil Model, strength parameters are the same, but stiffness parameters are different. These models could lead to more accurate results because of considering factors such as stiffness definition and difference in loading/ unloading stiffness. However, difference between the results of these two models would be noticeable when the tunnels have been excavated in high depths, so by increasing the depth of tunnels the surface settlement amounts decreases notably. In contrast, when the tunnels are being excavated in low depths, the surface settlement amounts don't change significantly by depth variations. Thus, because of the simplicity of formulation as well as the lesser data input determined by simple tests, MC model has more applications in simulation of shallow tunnels than other models, and since each soil layer is estimated by a constant average stiffness, computations with the MC model are relatively fast. It should also be noted that the live load of $20 \mathrm{kPa}$ was considered to apply as surface load in the model.

Table 2 Support properties

\begin{tabular}{lcccc}
\hline & $\mathrm{I}_{\mathrm{Y}}\left(\mathrm{m}^{4}\right)$ & $\mathrm{I}_{\mathrm{Z}}\left(\mathrm{m}^{4}\right)$ & $\mathrm{A}\left(\mathrm{m}^{2}\right)$ & $\mathrm{v}(\mathrm{GPa})$ \\
\hline Steel pipes & $10^{-6} \times 36.416$ & $10^{-6} \times 36.416$ & $10^{-3} \times 29.498$ & 20 \\
Lattice girder & $10^{-6} \times 11.1242$ & $10^{-6} \times 11.1242$ & $10^{-3} \times 1.963$ & 0.25 \\
shotcrete & - & - & - & 0.25 \\
\hline
\end{tabular}




\section{Analysis of load on tunnel support system}

As the pipe roofing method is usually considered as one of the expensive pre-supporting methods, investigations have to be done to balance economic and technical issues in a tunnel project. This could be accomplished by creating stabilization mechanism, defining implication domain, determining designing properties and meeting the requirements for safe domain to extend the model. Prior to analysis, in order to have perspective of initial condition and supporting system and realizing possible problems, firstly, the tunnel was modeled as a singular one. This model illustrates general view of effective parameters in planning the second phase of Istanbul twin tunnels. The intersection of singular tunnel is illustrated in Fig. 4.

After carrying out the analysis, the following supporting system was suggested:

1. Pipe roofing system: the number of pipes $=23$, $\mathrm{D}=114.3 \mathrm{~mm}$, spacing between pipes: $40 \mathrm{~cm}$, overlap-ping: $3 \mathrm{~m}$.

2. Shotcrete lining: thickness $=25 \mathrm{~cm}$.

3. Lattice girder: $25 \mathrm{~mm}$ in diameter and spacing $=15 \mathrm{~cm}$.

According to excavation method, after installation of presupporting system, first the upper bench of the first tunnel was excavated and supporting system, lining, shotcrete and lattice girder, were installed. Then at a distance about $2.4 \mathrm{~m}$ from the upper bench, the lower bench was excavated and the supporting system was set. This method proceeded till $\mathrm{y}=6 \mathrm{~m}$ and then pre-supporting system which is $9 \mathrm{~m}$ in length with $3 \mathrm{~m}$ overlapping was installed. The same process of excavation was applied to the second tunnel. The counter of z-displacement for the singular tunnel is shown in Fig. 5.

Figs. 6 and 7 show normal forces and bending moments induced on singular tunnel support system after excavation of $30 \mathrm{~m}$ of tunnel length. It is clear that the bending moments and normal forces are in acceptable range and the pipe roofing system and lattice griders are applied correctly.

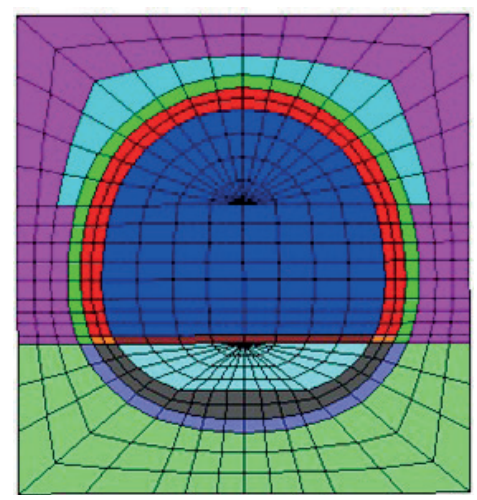

Fig. 4 Intersection of the singular tunnel

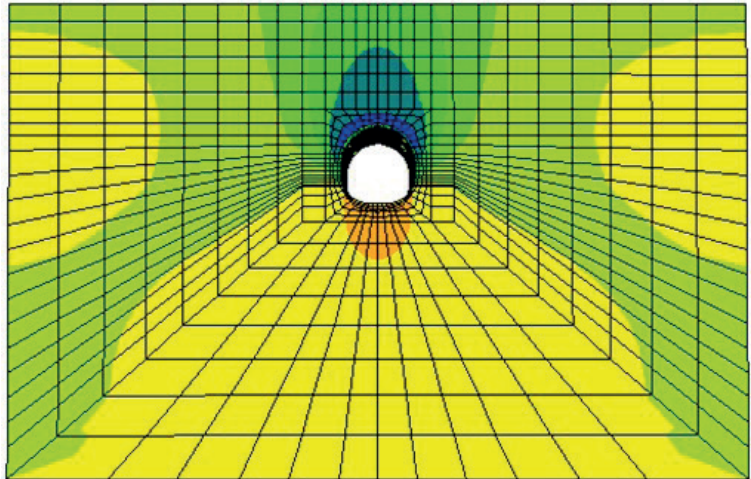

(a)

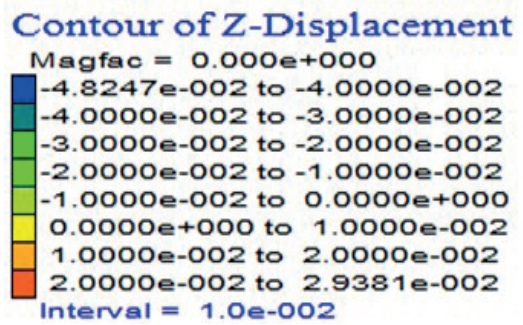

Fig. 5 Counters of z- displacement for the singular tunnel

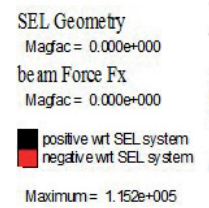

Maximum $=1.1520+005$

SEL Geometry

$\begin{aligned} & \text { Magac }=0.000 \mathrm{e}+000 \\ & \text { be am Moment My }\end{aligned}$ Magac $=0.000 \mathrm{e}+000$

positive wrt SEL system Maximum $=1.811 \mathrm{e}+004$

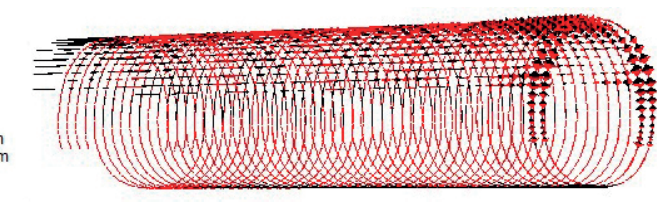

(b)

Fig. 6 Normal forces and bending moments in the lattice girders

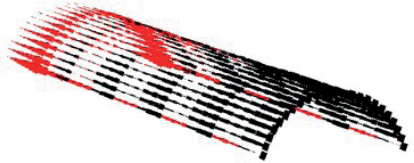

beam Force Fx Magfac $=0.000 \mathrm{e}+000$ positive wrt SEL system
negativewrt SEL system Maximum $=1.273 \mathrm{e}+005$

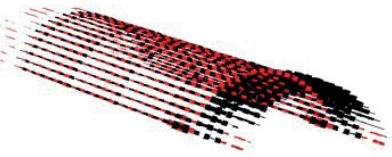

beam Force $\mathrm{Fz}$ positive wrt SEL system
negative wrt SEL system Maximum $=5.035 e+004$

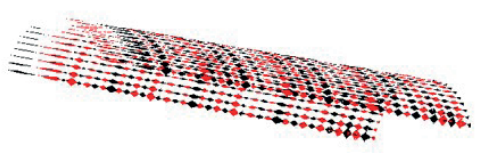

beam Moment Mz Magiac $=0.0000+000$

positive wrt SEL system Maximum $=9.719 \mathrm{e}+003$

Fig. 7 Normal forces and bending moments in the steel pipes 


\section{Investigation of the influence of tunnel spacing on surface settlement}

One of the most important parameters affecting interaction between tunnels is the tunnel face spacing. In order to take it into consideration, three different conditions were considered, various spacing in the direction perpendicular to tunnel axis, parallel to tunnel axis, and when the excavation of twin tunnels are performed at the same time.

The spacing between twin tunnels in analysis are considered as $\mathrm{L}_{\mathrm{S}}$ in the direction perpendicular to tunnel axis and $\mathrm{L}_{\mathrm{T}}$ in the parallel direction to tunnel axis Fig. 8.

In order to investigate the effect of these parameters on the stability of tunnel face and surface settlement, sensitivity analysis was carried out. To do so, $\mathrm{L}_{\mathrm{S}}$ was studied in 6 different conditions: 1.5D, 2D, 2.5D, 3D, 4D, 5D; whereas, $\mathrm{L}_{\mathrm{T}}$ at each of these conditions was $1 \mathrm{D}, 2 \mathrm{D}$, and 3D. Moreover, in order to investigate the effect of twin tunnels excavation on surface settlement, the related analysis with the assumption that the tunnels were excavated at the same time were considered. By doing analysis, it was noted that the excavation of the second tunnel influences the existing interactions on the first tunnel. This impact is more effective on the surface settlement curve. By the excavation of the second tunnel, the surface settlement curve moves toward the second tunnel. It is due to the induced weak zone around the first tunnel and between tunnels, as well. This weakened zone due to excavation of the first tunnel influences the ground between twin tunnels.

When the twin tunnels are being excavated at the same time, all the settlement graphs have symmetrical shapes and the maximum surface settlement happens exactly at the middle of the distance between twin tunnels $\left(\mathrm{L}_{\mathrm{S}} / 2\right)$ on the ground. As the distance between tunnels increases, the maximum surface settlement is shifted toward the crown of the tunnels and occurs at the same distance from tunnel centers for all cases. From the distance $\mathrm{L}_{\mathrm{S}}=4 \mathrm{D}$ the maximum surface settlement on the ground happens exactly at top of the crown of the tunnels Fig. 9.

In this part of analysis, the interaction between twin tunnels was investigated when $\mathrm{L}_{\mathrm{T}}=6 \mathrm{~m}$ (1D). In this mode, the excavation of the second tunnel causes surface

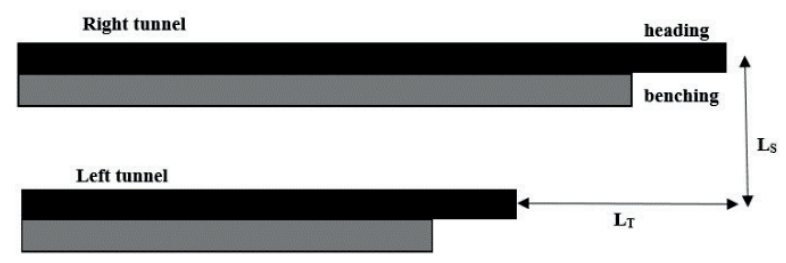

Fig. 8 Schematic spacing between twin tunnels

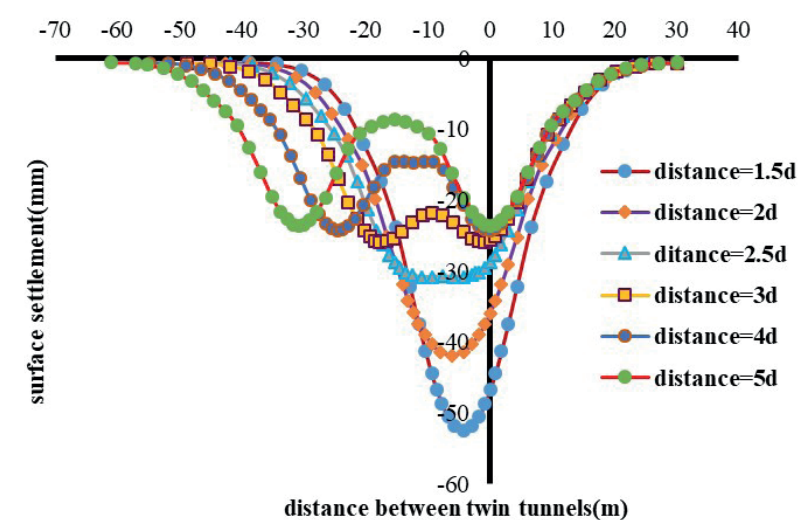

Fig. 9 The settlement pattern for spacing variation when $L_{T}=0$ found by flac3d

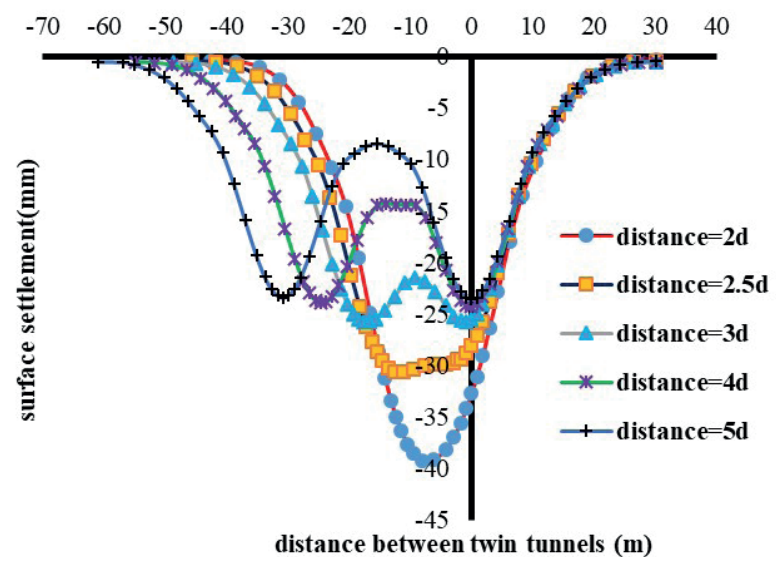

Fig. 10 The settlement pattern for spacing variation when $L_{T}=1 D$ found by flac3d

settlements to move toward the following tunnel and the amount of settlement at the mid zone increases till $\mathrm{L}_{\mathrm{S}}=4 \mathrm{D}$. At $\mathrm{L}_{\mathrm{S}}=3 \mathrm{D}$ the influence of induced weak zone decreases but it doesn't disappear completely, and the maximum surface settlement on the ground happens at a distance about $83 \mathrm{~cm}$ from the center of the first tunnel and $83 \mathrm{~cm}$ from the center of the second tunnel. Therefore, it can be stated that at $\mathrm{L}_{\mathrm{S}}=3 \mathrm{D}$ and $\mathrm{L}_{\mathrm{T}}=1 \mathrm{D}$ there is a same condition in maximum surface settlement amounts above tunnels, and since the leading tunnel is $6 \mathrm{~m}$ ahead of following tunnel, the interaction between twin tunnels doesn't disappear completely as shown in Fig. 10.

The maximum surface settlement above the twin tunnels for $\mathrm{L}_{\mathrm{T}}=1 \mathrm{D}$ are presented in Table 3 .

By the excavation of second tunnel at $\mathrm{L}_{\mathrm{S}}=1.5 \mathrm{D}$ and $\mathrm{L}_{\mathrm{T}}=2 \mathrm{D}$, the surface settlement curve shifts toward the second tunnel and the surface settlement reaches the maximum amount of $43.9 \mathrm{~mm}$ at a distance of $5.68 \mathrm{~m}$ from the first tunnel center. On the other hand, the settlement at top of the first tunnel and the second tunnel on the ground is about 36.8 and $40.5 \mathrm{~mm}$, respectively. When the distance 
Table 3 Comparison of surface settlements above the first and second tunnels for $\mathrm{L}_{\mathrm{T}}=1 \mathrm{D}$

\begin{tabular}{lcc}
\hline $\mathrm{L}_{\mathrm{S}}(\mathrm{m})$ & $\begin{array}{c}\text { Surface settlement above } \\
\text { the first tunnel }(\mathrm{mm})\end{array}$ & $\begin{array}{c}\text { Surface settlement above } \\
\text { the second tunnel }(\mathrm{mm})\end{array}$ \\
\hline 2D & 32.7 & 35.0 \\
2.5D & 28.0 & 28.7 \\
3D & 25.5 & 25.5 \\
4D & 24.2 & 23.9 \\
$5 \mathrm{D}$ & 23.5 & 23.3 \\
\hline
\end{tabular}

between twin tunnels are $\mathrm{L}_{\mathrm{S}}=2 \mathrm{D}$ and $\mathrm{L}_{\mathrm{T}}=2 \mathrm{D}$, the amount of surface settlement compared to the early position has decreased and the settlement curve has shifted toward the second tunnel. The amount of settlement at the distance of $8.3 \mathrm{~m}$ from the centerline of advanced tunnel is about $37.5 \mathrm{~mm}$ and the amount of settlement above the first and second tunnel is about 31.5 and $33.6 \mathrm{~mm}$, respectfully. At the distance of $\mathrm{L}_{\mathrm{S}}=2.5 \mathrm{D}$ and $\mathrm{L}_{\mathrm{T}}=2 \mathrm{D}$, the surface settlement curve starts to separation. This means that at this distance the interaction between twin tunnels decreases. At the distance of $\mathrm{L}_{\mathrm{S}}=3 \mathrm{D}$, the surface settlement curve of twin tunnels separates from each other, and the maximum surface settlement happens at the distance of $0.83 \mathrm{~m}$ from the first tunnel center and is about $25.2 \mathrm{~mm}$.

The amount of settlement above the first and second tunnel is about 25 and $24.7 \mathrm{~mm}$ respectfully. The amount of surface settlement above the first tunnel is more than second tunnel. Thus, it can be concluded that from $18.48 \mathrm{~m}$, the effect of disturbed zone due to excavation of the first tunnel decreases and the amount of settlement due to excavation of the first tunnel which is $12 \mathrm{~m}$ ahead increases.

At the distance of $\mathrm{L}_{\mathrm{S}}=4 \mathrm{D}$ the maximum amount of settlement occurs above the leading tunnel which is about $24.2 \mathrm{~mm}$, whereas the amount of settlement above the following tunnel on the ground is $23.2 \mathrm{~mm}$. The same condition can be seen when the distance between tunnels is increased to $\mathrm{L}_{\mathrm{S}}=5 \mathrm{D}$ when $\mathrm{L}_{\mathrm{T}}$ is $2 \mathrm{D}$, and this is the distance which Istanbul Twin Metro Tunnels were excavated. The maximum surface settlement has been found to be $23.5 \mathrm{~mm}$ at this distance Fig. 11.

The amounts of maximum surface settlements above the tunnels are given in Table 4 for $\mathrm{L}_{\mathrm{T}}=2 \mathrm{D}$ and $\mathrm{L}_{\mathrm{S}}=5 \mathrm{D}$.

When the lagging distance between twin tunnels is $\mathrm{L}_{\mathrm{T}}=3 \mathrm{D}$, at the distances of $\mathrm{L}_{\mathrm{S}}=2 \mathrm{D}$ and $\mathrm{L}_{\mathrm{S}}=2.5 \mathrm{D}$ the interaction between twin tunnels is noticeable and the settlement curve after excavation of the second tunnel, is shifted toward the following tunnel. At the distance of $\mathrm{L}_{\mathrm{S}}=3 \mathrm{D}$, Fig. 12, in respect to the fact that the longitudinal distance of working face has increased, the amount of

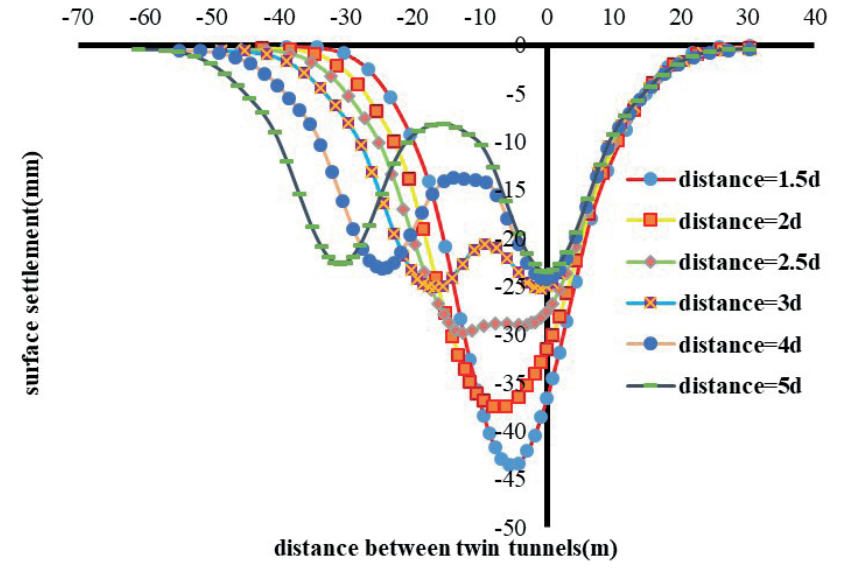

Fig. 11 The settlement pattern for spacing variation when $L_{T}=2 D$ found by flac3d

Table 4 Comparison of surface settlements above the first and second tunnels for $\mathrm{L}_{\mathrm{T}}=2 \mathrm{D}$

\begin{tabular}{ccc}
\hline $\mathrm{L}_{\mathrm{s}}(\mathrm{m})$ & $\begin{array}{c}\text { Surface settlement above } \\
\text { the first tunnel }(\mathrm{mm})\end{array}$ & $\begin{array}{c}\text { Surface settlement above } \\
\text { the second tunnel(mm) }\end{array}$ \\
\hline $1.5 \mathrm{D}$ & 36.6 & 40.2 \\
2D & 31.5 & 33.6 \\
$2.5 \mathrm{D}$ & 27.6 & 27.9 \\
3D & 25.0 & 24.7 \\
4D & 24.2 & 23.2 \\
5D & 23.5 & 22.7 \\
\hline
\end{tabular}

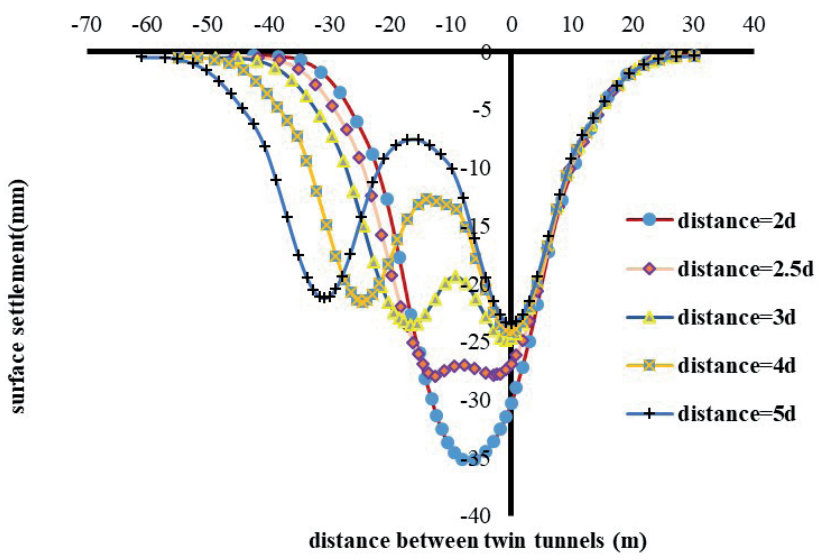

Fig. 12 the settlement pattern for spacing variation when $L_{T}=3 D$ found by flac3d

settlement above the leading tunnel is more than following tunnel; however, due to the spacing effect of tunnels, this amount is not equal to the maximum surface settlement. At $\mathrm{L}_{\mathrm{S}}=4 \mathrm{D}(24.64 \mathrm{~m})$, the point with maximum settlement moves toward the first tunnel.

After this stage, settlement curves are less sensitive to the changes in $\mathrm{L}_{\mathrm{S}}$ and the interaction between tunnels decreases. Table 5 shows the maximum surface settlements on top of the first and second tunnel on the ground for $\mathrm{L}_{\mathrm{T}}=3 \mathrm{D}$. 
Table 5 Comparison of surface settlements above the first and second tunnels for $\mathrm{L}_{\mathrm{T}}=3 \mathrm{D}$

\begin{tabular}{ccc}
\hline $\mathrm{L}_{\mathrm{S}}(\mathrm{m})$ & $\begin{array}{c}\text { Surface settlement above } \\
\text { the first tunnel }(\mathrm{mm})\end{array}$ & $\begin{array}{c}\text { Surface settlement above } \\
\text { the second tunnel }(\mathrm{mm})\end{array}$ \\
\hline 2D & 30.2 & 31.3 \\
$2.5 \mathrm{D}$ & 26.8 & 26.0 \\
3D & 24.7 & 22.9 \\
4D & 21.4 & 21.5 \\
5D & 23.4 & 21.2 \\
\hline
\end{tabular}

Table 6 maximum surface settlement values according to surface monitoring points in studied section [17]

\begin{tabular}{lc}
\hline SMP no & $\mathrm{S}_{\max }$ measured $(\mathrm{mm})$ \\
\hline 5043 & 26.53 \\
$5043 \mathrm{~A}$ & 27.79 \\
5039 & 27.90 \\
5063 & 27.92 \\
5045 & 28.18 \\
5067 & 25.34 \\
5065 & 26.60 \\
\hline
\end{tabular}

When the excavation of twin tunnels is completed, the surface settlement measurements are conducted at some points on the ground [14]. The maximum settlement amounts are presented in Table 6 [17].

The distance between twin tunnels in this section is about $30 \mathrm{~m}$. At this distance, the interaction between twin tunnels has disappeared and they behave like singular ones. The maximum surface settlement obtained from flac3d is the same for the advanced tunnel and the singular tunnel, and they are in good consistency with field measurements.

Comparing the maximum surface settlement obtained from numerical simulation, which is about $23.5 \mathrm{~mm}$, with monitoring data reveals that there is a good agreement between the results as the maximum surface settlement observed from surface monitoring points is $26.5 \mathrm{~mm}$ at studied point (5043 on Fig. 13).

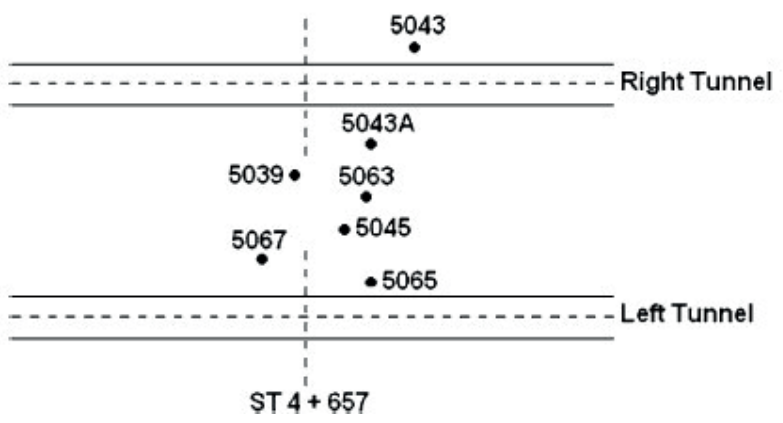

Fig. 13 locations of monitoring points [17]
Figs. 14 and 15 show the variation of settlement profile above tunnels and the maximum amount of settlement between twin tunnels for different $\mathrm{L}_{\mathrm{S}}$ amounts as $\mathrm{L}_{\mathrm{T}}$ increases. It is clear that for all $\mathrm{L}_{\mathrm{S}}$ amounts when the lagging distance between tunnels increases, the amount of surface settlement decreases. However, the effect of distance between twin tunnels for $\mathrm{L}_{\mathrm{S}}=2 \mathrm{D}(12.32 \mathrm{~m})$ and $\mathrm{L}_{\mathrm{S}}=2.5 \mathrm{D}(15.4 \mathrm{~m})$ is much more than other conditions. Thus, considering the interaction effect of twin tunnels in the direction parallel to tunnel axis shows that the excavation of these tunnels at the distance $\mathrm{L}_{\mathrm{S}}=2 \mathrm{D}$ and $\mathrm{L}_{\mathrm{S}}=2.5 \mathrm{D}$ is not feasible because the change of this distance causes the large settlement on the ground surface and increase in settlement profile.

\section{Conclusions}

Based on analysis, the results obtained from numerical model are in good agreement with the settlement monitoring data. The maximum amount of settlement obtained by numerical method is about $23.5 \mathrm{~mm}$ which is close to the maximum surface settlement of $26.5 \mathrm{~mm}$ by monitoring. It is concluded that the excavation of the first tunnel causes a weak zoon around it and also in the region between twin tunnels. This disturbed zoon due to the first tunnel excavation, has remarkable influences on the ground settlement as the second tunnel is being excavated.

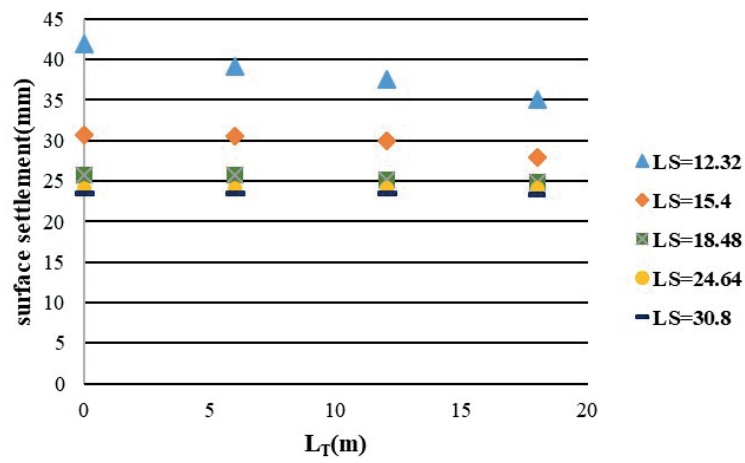

Fig. 14 Variation of the surface settlement with $\mathrm{L}_{\mathrm{T}}$ for different amounts of $\mathrm{L}_{\mathrm{S}}$ above the first tunnel

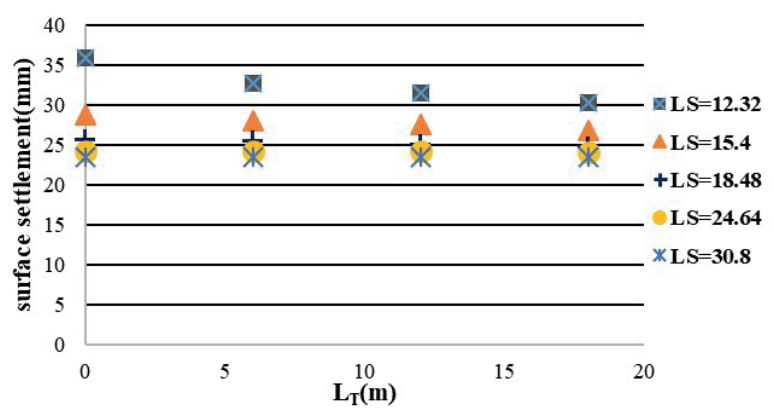

Fig. 15 Variation of the maximum surface settlement with $\mathrm{L}_{\mathrm{T}}$ for different amounts of $L_{S}$ 
The most important difference between the settlement pattern on the ground above the first and second tunnel is higher amounts of settlements on top of the second tunnel at the beginning of the excavation because of creation of this weakened zone till a definite longitudinal distance between twin tunnels.

As the amount of $\mathrm{L}_{\mathrm{T}}$ Increases, the amount of settlement decreases; However, at distance of $\mathrm{L}_{\mathrm{S}}=2 \mathrm{D}$ and $\mathrm{L}_{\mathrm{S}}=2.5 \mathrm{D}$ even by increasing the distance between tunnel faces in longitudinal direction to $\mathrm{L}_{\mathrm{T}}=3 \mathrm{D}$, the effect of disturbed zoon doesn't disappear.

\section{References}

[1] Soliman, E., Duddeck, H., Ahrens, H. "Two and three-dimensional analysis of closely spaced double-tube tunnels", Tunnelling Underground Space Technology, 8(1), pp. 13-18, 1993. https://doi.org/10.1016/0886-7798(93)90130-N

[2] Kawata, T., Ohtsuka, M., Kobayashi, M. "Observational construction of large scaled twin road tunnels with minimum interval", In: AFTES - Technical Days, Toulon, France, 1993, pp. 241-248.

[3] Perri, G. "Analysis of the effects of the new twin-tunnels excavation very close to a big diameter tunnel of Caracas Subway", In: Tunnelling and Ground Conditions : proceedings of the International Congress on Tunnelling and Ground Conditions, Cairo, Egypt, 1994, pp. 523-530.

[4] Saitoh, A., Gomi, K., Shiraishi, T. "Influence forecast and field measurement of a tunnel excavation crossing right above existing tunnels", In: Tunnelling and Ground Conditions: proceedings of the International Congress on Tunnelling and Ground Conditions, Cairo, Egypt, 1994, pp. 83-92.

[5] Shahrour, I., Mroueh, H. "Three-dimensional nonlinear analysis of a closely twin tunnels", In: Numerical Models in Geomechanics: Proceedings of the 6th international symposium (NUMOG VI), Montreal, QC, Canada, 1997, pp. 481-487.

[6] Yamaguchi, I., Yamazaki, I., Kiritani, K. "Study of ground-tunnel interactions of four shield tunnels driven in close proximity, in relation to design and constructions of parallel shield tunnels", Tunnelling and Underground Space Technology, 13(3), pp. 289-304, 1998. https://doi.org/10.1016/S0886-7798(98)00063-7

[7] Addenbrooke, T. I., Potts, D. M. "Twin Tunnel interaction: Surface and Subsurface Effects", The International Journal of Geomechanics, 1(2), pp. 249-271, 2001. https://doi.org/10.1061/(ASCE)1532-3641(2001)1:2(249)

[8] Karakus, M., Ozsan, A., Basarir, H. "Finite element analysis for the twin metro tunnel constructed in Ankara Clay, Turkey", Bulletin of Engineering Geology Environment, 66(1), pp. 71-79, 2007. https://doi.org/10.1007/s10064-006-0056-z

[9] Hage Chehade, F., Shahrour, I. "Numerical analysis of the interaction between twin tunnels: Influence of the relative position and construction procedure", Tunnelling and Underground Space Technology, 23(2), pp. 210-214, 2008. https://doi.org/10.1016/j.tust.2007.03.004
For all $\mathrm{L}_{\mathrm{S}}$ amounts, as $\mathrm{L}_{\mathrm{T}}$ increases, the amount of settlement decreases, but the influence of this parameter at $\mathrm{L}_{\mathrm{S}}=2 \mathrm{D}$ and $2.5 \mathrm{D}$ is more remarkable. Considering interaction effect between tunnels in direction of tunnel axis, excavation of twin tunnels at $\mathrm{L}_{\mathrm{S}}=1.5 \mathrm{D}, \mathrm{L}_{\mathrm{S}}=2 \mathrm{D}$, and $\mathrm{L}_{\mathrm{S}}=2.5 \mathrm{D}$ is not possible. The reason is that with variation at distance, the amount of settlement varies significantly.

\section{Acknowledgement}

Authors would like to express their sincere and special thanks to Dr. Balázs Vásárhelyi for his thorough review and constructive remarks in doing this research.

[10] Liu, H. Y., Small, J. C., Carter, J. P., Williams, D. J. "Effects of tunnelling on existing support systems of perpendicularly crossing tunnels", Computers and Geotechnics, 36(5), pp. 880-894, 2009. https://doi.org/10.1016/j.compgeo.2009.01.013

[11] Kim, S. H., Burd, H. J., Milligan, G. W. E. "Model testing of closely spaced tunnels in clay", Géotechnique, 48(3), pp. 375-388, 1998. https://doi.org/10.1680/geot.1998.48.3.375

[12] Ng, C. W. W., Lee, K. M., Tang, D. K. W. "Three-dimensional numerical investigations of new Austrian tunnelling method (NATM) twin tunnel interactions", Canadian Geotechnical Journal, 41(3), pp. 523-539, 2004.

https://doi.org/10.1139/T04-008

[13] Chapman, D. N., Ahn, S. K., Hunt, D. V. L. "Investigating ground movements caused by the construction of multiple tunnels in soft ground using laboratory model tests", Canadian Geotechnical Journal, 44(6), pp. 631-643, 2007. https://doi.org/10.1139/t07-018

[14] Ahmadi, M. H., Davoodi, H. "A micromechanical SlidingDamage Model Under Dynamic Compressive Loading", Periodica Polytechnica Civil Engineering, 63(1), pp. 168-183, 2019. https://doi.org/10.3311/PPci.13249

[15] Ocak, I. "Control of surface settlements with umbrella arch method in second stage excavations of Istanbul Metro", Tunnelling and Underground Space Technology, 23(6), pp. 674-681, 2008. https://doi.org/10.1016/j.tust.2007.12.005

[16] Chakeri, H., Hasanpour, R., Hindistan, M. A., Ünver, B. "Analysis of interaction between tunnels in soft ground by $3 \mathrm{D}$ numerical modeling", Bulletin of Engineering Geology Environment, 70(3), pp. 439-448, 2011. https://doi.org/10.1007/s10064-010-0333-8

[17] Ercelebi, S. G., Copur, H., Ocak, I. "Surface settlement predictions for Istanbul Metro tunnels excavated by EPB-TBM", Environmental Earth Sciences, 62(2), pp. 357-365, 2011. https://doi.org/10.1007/s12665-010-0530-6

[18] Hasanpour, R., Chakeri, H., Ozcelik, Y., Denek, H. "Evaluation of surface settlements in the Istanbul metro in terms of analytical, numerical and direct measurements", Bulletin of Engineering Geology and the Environment, 70(3), pp. 499-510, 2012. https://doi.org/10.1007/s10064-012-0428-5 
[19] Ocak, I. "A new approach for estimating the transverse surface settlementcurve for twin tunnels in shallow and soft soils", Environmental Earth Scieances, 72(7), pp. 2357-2367. https://doi.org/10.1007/s12665-014-3145-5

[20] Ma, L., Ding, L., Luo, H. "Non-linear description of ground settlement over twin tunnels in soil", Tunnelling and Underground Space Technology, 42, pp. 144-151, 2014 https://doi.org/10.1016/j.tust.2014.02.006

[21] Fang, Q., Tai, Q., Zhang, D., Wong, L. N. W. "Ground surface settlements due to construction of closely-spaced twin tunnels with different geometric arrangements", Tunnelling and Underground Space Technology, 51, pp. 144-151, 2016. https://doi.org/10.1016/j.tust.2015.10.031
[22] Narimani, S., Chakeri, H., Davarpanah, S. M. "Simple and NonLinear Regression Techniques Used in Sandy-Clayey Soils to Predict the Pressuremeter Modulus and Limit Pressure: A Case Study of Tabriz Subway", Periodica Polytechnica Civil Engineering, 62(3), pp. 825-839, 2018. https://doi.org/10.3311/PPci.12063

[23] Usta, E. "Istanbul Metro Yenikapi-Unkapani engineering geology", Master thesis, Istanbul Technical University, 2004.

[24] Ercelebi, S. G., Copur, H., Bilgin, N., Feridunoglu, C. "Surface settlement prediction for Istanbul metro tunnels via 3D FE and empirical methods", In: Erdem, S., Solak, T. (eds.) Underground Space Use: Analysis of the Past and Lessons for the Future, Taylor \& Francis Group, London, UK, pp. 163-169. [online] Available at: https://www.taylorfrancis.com/books/e/9780429107481 [Accessed: 03 October 2019] 